\title{
Saberes da formação profissional: um estudo ator-rede quanto à performance da prática de professores em formação
}

\author{
Professional Education Knowledge: An actor-network study of a \\ performance of prospective teachers' practices.
}

\author{
Bruno Venancio (brunovenanciob@gmail.com) \\ Programa de Pós-graduação em Educação (PPGEdu) da Universidade Federal Fluminense \\ (UFF). \\ Gabriel Menezes Viana (gabrielviana@ufsj.edu.br) \\ Departamento de Ciências Naturais (DCNat) do Programa de Pós-graduação em Educação \\ (PPEdu).
}

Resumo: Para este texto, investigamos a apresentação de um planejamento de aula de professores de Ciências em formação e a interação com a professora-formadora. Como referencial teórico, adotamos o conceito de performance, conceituações sobre os saberes docentes e elementos da Teoria Ator-Rede. Objetivamos entender o que emerge nas interações quando pensamos sobre os conhecimentos ou saberes necessários para a docência ao serem performados em sala de aula. $\mathrm{O}$ estudo foi conduzido em um curso de Licenciatura em Ciências Biológicas de uma universidade pública situada no interior do estado de Minas Gerais durante o segundo semestre do ano de 2017. Os dados constaram de anotações em caderno de campo e gravações em áudio e vídeo. As análises foram conduzidas sobre as transcrições das interações em sala de aula. Nossos resultados indicam que um elemento muito adotado pelos licenciandos em seus planejamentos, os conhecimentos prévios, apresentou modos de atuação diversos quando se associou a diferentes actantes, promovendo, assim, efeitos distintos na rede de associações em sala de aula e, em consequência, nos conhecimentos produzidos.

Palavras-chave: Formação de Professores de Ciências; Performance; Saberes Docentes; Teoria Ator-Rede.

Abstract: For this text, we investigated the presentation of a lesson plan from science
teacher`s practice and the interaction with the practice-teacher. As a theoretical
framework, we adopted the performance concept, conceptions about the knowledge
teacher`s and Actor Network Theory elements. We aimed to understand what emerge in
these interactions when we think about knowledge teacher`s when they performed in
class. The study was conducted in a course in a Biological Sciences Degree course at a
public University Program located in the state of Minas Gerais during a second semester
of 2017 . The data consisted of notes in a field notebook and audio and video recordings.
Our results indicate that an element widely adopted by undergraduates in their planning,
previous knowledge, presented different modes of action when associated with different 
actors, thus promoting different effects on the network of associations in the classroom and, consequently, on knowledge produced.

Keywords: Science Teaching Practices; Performance; Knowledge Teaching; Actor Network Theory.

\section{INTRODUÇÃO}

Este texto traz alguns resultados de uma pesquisa conduzida em um curso de mestrado acadêmico em Educação, que se propôs a investigar a Prática como Componente Curricular (PCC) (BRASIL, 2002a, 2002b, 2015, 2019), um importante elemento que foi instituído pelas normativas, as quais orientam a formação de professores em nosso país. Mais especificamente, estivemos interessados em perceber como ocorre a performance (SØRENSEN, 2009) da PCC quando ela é assumida enquanto uma dimensão curricular em uma disciplina de Prática de Ensino de Ciências. O estudo foi conduzido em um curso de Licenciatura em Ciências Biológicas de uma universidade pública situada no interior do estado de Minas Gerais durante o segundo semestre do ano de 2017. Para este texto, selecionamos o momento em que a performance dessa prática é construída em torno da apresentação de planejamentos de aula dos licenciandos e da intervenção da professora-formadora, numa situação em que as associações entre atores humanos e não humanos (LATOUR, 2012) localizaram a centralidade de um actante (LATOUR, 2000, 2012), os conhecimentos prévios, fazendo emergir aquilo que identificamos enquanto "saberes da formação profissional".

A prática como componente curricular (PCC), como se sabe, foi instituída a partir de das Diretrizes Curriculares Nacionais (DCN) para a formação de professores (BRASIL, 2002a, 2002b, 2015, 2019) nos anos 2001 e 2002 sendo mantida, com algumas alterações, nas diferentes versões que o documento ganhou nos últimos quase 20 anos. Uma das concepções propostas trazidas pelo documento para a PCC entende que a dimensão prática na formação do professor não se reduz à atuação dos licenciandos estando de corpo físico nas escolas, pois, para isso, compreendem-se os momentos do estágio curricular supervisionado (AYRES; VILELA; SELLES, 2020). Em outra direção, as diretrizes propõem que, também, podem ser entendidas como práticas as etapas de observação, preparação e reflexão e outras relativas à atividade 
profissional (BRASIL, 2002a). Além disso, como destacam Pereira e Mohr (2017, p. 28), o documento, ainda, sustenta que, nesses momentos, há uma "mobilização de conhecimentos e reflexão sobre a prática" e que a dimensão prática não deveria se restringir às disciplinas que contemplam os conteúdos pedagógicos. Tais perspectivas nos sugerem que essa ampliação do conceito de prática, também, aponta para uma atenção à dimensão da formação reflexiva quando se considera que essa prática oportuniza o surgimento de situações-problemas, que, ordinariamente, compõem o cotidiano da atuação docente.

De acordo com Gatti (2010) e Gatti e Barreto (2009), mesmo após a publicação das DCN para a Formação de Professores no início dos anos 2000, o foco conferido aos conhecimentos específicos das áreas de referência (ou dos conteúdos específicos de ensino) nos cursos de formação de professores acabam por dificultar a construção de um perfil de professor nos cursos de formação docente. Tal situação não é diferente na formação de professores em Ciências e Biologia, já que, conforme Ayres et al. (2020), as DCN, apesar de terem promovido uma superação do modelo " $3+1$ ” nesses cursos, ainda mantêm a valorização da racionalidade prática nesses cursos com uma diminuição das disciplinas de "Ciências da Educação" na formação do professor. Entretanto, destacam as autoras, também, avanços quando entendem que as DCN sinalizam para uma abertura de maior valorização do professor, do ambiente escolar e de seu contexto de trabalho. Além disso, nas versões mais atuais do documento (BRASIL, 2015), Ayres et al. (2020, p. 122) destacam uma atenção maior às Ciências Sociais e Humanas além de uma proposta de "valorização do desenvolvimento profissional docente". Além disso, é importante ressaltar as múltiplas interpretações sobre a PCC, e até mesmo em alguns casos a falta de seu entendimento quanto ao seu desenvolvimento, como sinalizado por alguns autores (VENANCIO; VIANA, 2016; BOTON; TOLENTINONETO, 2019).

Em nossa investigação, consideramos a PCC como um localizador (LATOUR, 2012), isto é, um elemento, ou uma entidade, que direciona para o lugar da ação, oportunizando, assim, condições para o entrelaçamento de outros autores e redes. Em nossa perspectiva, fundamentada nos estudos de Bruno Latour e de seus colaboradores, a PCC é uma entidade que confere espaço-tempo em que certas dimensões de prática na 
Edição Especial: I SSAPEC - Simpósio Sul-Americano de Pesquisa em Ensino de Ciências

ISSN: 2595- $4520 \quad$ Vol. 4, n. 3. 2021

formação de professores são produzidas e performadas, ganhando condições de existências ocasionalistas e relacionais (HARMAN, 2007).

\section{REFERENCIAIS TEÓRICOS}

A literatura do campo da formação de professores nos aponta uma diversidade de sentidos da prática (FERREIRA; VILELA; SELLES, 2003; TERRERI, 2008; TERRERI; FERREIRA, 2013; VIANA et al., 2015; VENANCIO; VIANA, 2016). Andrade et al. (2004) sustentam que as DCN promoveram uma abordagem da epistemologia da prática na formação de professores. Com isso, entende-se que conhecimentos e saberes acadêmicos são, também, produzidos nos momentos de prática.

Tardif (2000) é um dos nomes que se destacam quando pensamos sobre a diversidade e complexidade do conjunto de saberes mobilizados pelos professores em suas atividades profissionais quer seja no cotidiano da escola ou em outros espaços. Seus estudos e propostas nos permitem melhor investigar essa epistemologia da prática e ir percebendo saberes, os quais se formam nas interações práticas dos professores nos momentos de atividade profissional. Para Tardif (2000, p. 11), a proposta é compreender como os professores "incorporam, produzem, utilizam, aplicam e transformam" tendo em vista as peculiaridades inerentes ao fazer docente.

Tardif (2000, 2014), assim como outros autores (GAUTHIER et al., 2006; TARDIF; LESSARD, 2005) preconiza sobre a diversidade de saberes dos professores em atuação nos contextos escolares, como, por exemplo, os saberes relacionados a questões pedagógicas, de técnicas e métodos de ensino. Tardif $(2014$, p. 36) considera que esse "saber-fazer" dos docentes são complexos, já que se atuam entrelaçando saberes construídos em diferentes espaços-tempos "[...] um saber plural, formado pelo amálgama, mais ou menos coerente, de saberes oriundos da formação profissional e de saberes disciplinares, curriculares e experienciais". Propõe o autor que saberes disciplinares são aqueles concebidos dentro de uma área do conhecimento específica, como a linguagem, as ciências humanas, exatas e/ou biológicas. Esses saberes são produzidos e reunidos no decorrer da história, gerenciados pela comunidade científica e tendo seu acesso viabilizado por meio de instituições de ensino (TARDIF, 2014). Já os saberes curriculares dizem respeito à forma como as instituições administram os Recebido em: 18/01/2021 
conhecimentos produzidos e que devem chegar aos estudantes na forma de saberes disciplinares. Com isso, esses saberes se concretizam na forma de objetivos, conteúdos e métodos, os quais os professores aprendem, para que possam ser utilizados em sua profissão. Por fim, os saberes experimentais, segundo Tardif (2014), seriam o resultado da atuação docente por meio de situações, que são inerentes ao ambiente escolar, à sala de aula e aos alunos.

Outro relevante referencial teórico-conceitual e metodológico da pesquisa está ancorado na Teoria Ator-Rede (ANT, em inglês) proposta por Bruno Latour (2000, 2012) e Latour e Woolgar (1997). Para Fenwick e Edwards (2010), o estudo Ator-Rede em ambientes educacionais permite dar visibilidade a uma grande variedade de elementos que estão em jogo.

Com a ANT, dedicamos uma atenção muito especial à ação, compreendendo-a como assumida, ou seja, observando aquilo que aconteceu, e não como o que poderia ou deveria ser, assim como ela é distribuída por um coletivo de atores envolvendo não somente os humanos, mas também as ações de atores não humanos (LATOUR, 2000, 2012). Na ANT, aqueles que agem são denominados de actantes e se qualificam como mediadores ou intermediários dependendo de como conduzem as informações no fluxo da ação. Os primeiros são aqueles capazes de imprimirem alguma modificação na informação que transportam; já os segundos a conduzem sem modificá-la. O ponto central não é mais dizer "quem atua" e "como", mas nos direcionarmos para a incerteza da ação ao nos perguntarmos "o que atua e como" (LATOUR, 2000, 2012). Os actantes se articulam em redes por meio de vínculos, que tendem ora a se estabilizar, ora a se enfraquecer quando outros actantes são inseridos ou retirados da rede. Como resultado desses movimentos de (des)associação, a rede produz algum efeito no mundo, que pode ser estudado por meio de sua performance.

Em nossa investigação, também, foi fundamental o conceito de performance proposto por Sørensen (2009), pois nos fez entender a prática a partir daquilo que foi performado em sala de aula. Desse modo, em Sørensen (2009), a performance pode ser entendida como um resultado de uma assembleia sociomaterial, permitindo-nos questionar o que pôde ser obtido por meio de uma organização de elementos, os quais se "inter-relacionaram", atuaram ou participaram em determinada prática. Nesse sentido, a noção de participação - incluída na performance de Sørensen (2009) - remete 
a como um ator permite ou dá condições para que outro também atue. A performance, portanto, envolve um processo amplo e o produto/efeito não se reduz a um simples ato ou ação individual de um ator. Ela descreve uma variedade de componentes (como a realidade preexistente, o texto e a abordagem), que, juntos, formam uma assembleia sociomaterial (SØRENSEN, 2009). Na concepção de Silva e Coutinho (2016), o conceito de performance nos permite refletir sobre como o conhecimento é produzido e distribuído nas diferentes associações entre os atores.

Ao investigar, com a ANT, a Prática como Componente Curricular no Projeto Político Pedagógico (PPP) do curso de Licenciatura em Ciências Biológicas da Universidade Federal de São João del-Rei (UFSJ), Viana e Coutinho (2017) identificaram ações nos verbos utilizados ao longo do documento, que remeteram a três grupos de disciplinas vinculadas a três Departamentos da Universidade. Por exemplo, nas Práticas de Ensino (vinculadas ao Departamento de Ciências Naturais), a PCC se apresentava como principal verbo de “instrumentalizar". Já na disciplina de Psicologia da Educação (vinculada ao Departamento de Psicologia), os verbos indicavam ações de “analisar” e, na disciplina de Estrutura do Ensino no Brasil (vinculada ao Departamento de Ciências da Educação), as ações da PCC se expressavam no verbo "discutir". Portanto, segundo os autores, a performance da PCC no documento indicava modos de agir próprios dos campos de atuação profissional de cada área.

Também com a Teoria Ator-Rede (ANT), Venancio, Viana e Silva (2020) investigaram performances da PCC em uma disciplina de Prática de Ensino de Ciências. Em suas análises, notaram como as diferentes entidades que compõem os planejamentos de aula dos discentes permitem produzir realidades diversas. Em especial, eles observaram que, nessas apresentações, passado, presente e futuro se alteram e misturam como escolas reais e imaginadas. Ponderam os autores que, nos cursos de formação de professores, é imprescindível estar atento a como certos actantes são arregimentados e se articulam nas redes produzidas em salas de aula de modo que os licenciandos tenham uma base para construir seus planejamentos e ações pedagógicas sem se limitarem ou proibirem imaginar e inventar.

Diante do exposto, a pesquisa que fundamentou este texto se propôs a entender algumas questões: o que emerge nas associações entre licenciandos, professoraformadora, conteúdo de ensino, lugares e outros objetos durante as interações em uma 
Edição Especial: I SSAPEC - Simpósio Sul-Americano de Pesquisa em Ensino de Ciências

ISSN: 2595- $4520 \quad$ Vol. 4, n. 3. 2021

disciplina de Prática de Ensino durante as apresentações de planos de aula de futuros professores de Ciências e Biologia? Quais saberes docentes seriam performados durante um espaço-tempo curricular assumido pela Instituição como de prática como componente curricular?

\section{PERCURSO METODOLÓGICO}

A pesquisa está localizada dentro do amplo espectro das pesquisas qualitativas em Educação (BOGDAN; BIKLEN, 1994), pois considera a natureza do fenômeno investigado, as experiências compartilhadas entre atores humanos e não humanos, como eminentemente qualitativa.

O campo de pesquisa compreendeu uma disciplina obrigatória de um curso de Licenciatura em Ciências Biológicas intitulada "Prática de Ensino de Ciências", com carga horária de 36 horas, que fora escolhido para investigação, uma vez que contemplava carga horária da prática como componente curricular (PCC). O objetivo da disciplina era que os licenciandos elaborassem e apresentassem aos colegas planos de aulas de Ciências para os níveis finais do Ensino Fundamental, em torno de dois grandes temas: "Meio Ambiente" e "Saúde".

Para a coleta de dados, utilizamos registros em caderno de campo e gravações em vídeos e áudio durante todos os momentos de aula. Os materiais considerados mais importantes foram transcritos para posteriores análises, a partir do que Latour (2012) sinaliza que não é explicar o que o eles estão fazendo, mas sim, de descrever o que estão fazendo. Além disso, fizemos uso da observação participante (LÜDKE; ANDRÉ, 2017, p. 31), quando o observador se propõe a desenvolver um olhar analítico na "perspectiva do sujeito" no instante da condução de suas atividades cotidianas, seguindo de perto aqueles que estão envolvidos nas construções de redes sociotécnicas, no dinamismo e no movimento dos atores (LATOUR, 2000, 2012; LATOUR, WOOLGAR, 1997).

A ANT muito se desenvolveu a partir dos estudos da Antropologia e, em especial, da Etnografia. Nesse contexto, a adoção de uma observação participante, também, se propõe a compreender o modo de ser e estar dos atores locais considerando em suas ações as significações para os membros daquele local. No entanto, Latour (1997, 2000, 2012) considera que é preciso "colocar entre parênteses" as visões dos 
sujeitos investigados. Isto é, o pesquisador não deve acreditar em tudo que é dito tal como é enunciado pelos atores, mas se atentar para aquilo que eles fazem. Em sua etnografia sobre cientistas de um laboratório, ele coloca nos seguintes termos: “[...] precisamos nos ater mais do que nunca a nosso método de observar apenas a prática dos cientistas, permanecendo surdos a opiniões, tradições filosóficas e até mesmo àquilo que os cientistas dizem acerca do que fazem" (LATOUR, 2000, p. 144).

Dessa forma, ao estar presente em uma sala de aula durante toda uma disciplina, foi primordial analisar de perto os participantes, observando o que eles falavam, como falavam, mas atentos, em especial, para acompanhar como faziam. De forma a manter o anonimato, os nomes dos licenciados foram substituídos por pseudônimos.

\section{RESULTADOS E DISCUSSÕES}

Para as análises que ocorrem a seguir, daremos destaque a uma passagem em que um elemento, que se fez presente em muitos planejamentos de aula de Ciências para o Ensino Fundamental dos licenciandos, tem significativo protagonismo: os "conhecimentos prévios". Para isso, elencamos, nas apresentações em sala de aula, um trecho em que há uma interação entre licenciandos e professora-formadora. Nesse exemplo, de acordo com os referenciais teóricos adotados na pesquisa, consideramos que se fizeram emergir, enquanto efeito da rede, performances da prática quanto aos saberes da formação profissional. Nesse instante, entendemos que os actantes, os quais compõem a rede sociotécnica da sala de aula, produzem efeitos que remetem a conhecimentos e saberes sobre a futura atuação docente dos licenciandos nas escolas.

O exemplo inicia com Brenda, uma licencianda, que, ao apresentar a organização de seu planejamento de aula sobre o conteúdo de Citologia (ciência das células), faz referência ao "conhecimento prévio" dos estudantes da educação básica e como eles influenciariam nos sequenciamentos das aulas:

O conteúdo é célula, matéria de $8^{\circ}$ ano e na primeira aula a gente vai a gente vai ver o que os alunos têm de conhecimento prévio. A gente vai perguntar 'o que é uma célula?' 'como sabemos que elas existem?' 'como as células se organizam?' 'Todos os seres vivos possuem célula?' 'todas as células são iguais?' De acordo com as respostas, a gente ia montar as outras aulas e a gente ia explicando também (Brenda 04/10/2017 0:57, lê o que estava escrito na lousa - grifo nosso). 
Inicialmente, percebemos que há uma demarcação curricular quando Brenda indica que o "conteúdo" de "célula" está presente no " $8^{\circ}$ ano". Este actante, o $8^{\circ}$ ano, atua localizando o conteúdo em níveis de ensino, já que se fala de uma célula específica: o conteúdo sobre célula de um nível escolar. Ela, portanto, nos dá indícios de movimentos em torno de saberes curriculares (TARDIF, 2014), que atuam, também, em conjunto com o conteúdo e as sequências das aulas. A licencianda administra a forma como o conteúdo disciplinar é organizado ou até mesmo "didatizado" (SELLES; FERREIRA, 2009) apontando direcionamos ao modo como o conteúdo será abordado. Na sequência, são apresentados a organização e o sequenciamento da aula "na primeira aula" e seu objetivo de analisar “o que os alunos têm de conhecimento prévio". Quando esses actantes passam a compor o planejamento, eles provocam uma mudança, porque é por meio deles que serão acionadas perguntas, tais como: “o que é uma célula?", “como sabemos que elas existem?", "como as células se organizam?”, “Todos os seres vivos possuem célula?" e "todas as células são iguais?" Assim, na perspectiva da licencianda que apresenta o plano de aula, é a partir do que os "alunos" responderem que o curso seguinte das aulas será conduzido. Este actante, o conhecimento prévio, age de forma a marcar uma orientação metodológica ou o que podemos considerar como uma "teoria do método", pois sua ação está associada a "instigar o conhecimento" ou o que os alunos já conhecem: "essa sondagem do que eles sabem", "ver o que eles sabem das coisas" e "perguntas para despertar".

Ao final da apresentação dos licenciandos, a professora-formadora, já atenta para a significativa presença dos conhecimentos prévios nos planejamentos de aulas dos professores em formação, aproveita para sinalizar algumas reflexões sobre a forma como eles estão sendo utilizados nesses momentos.

Todos os grupos, de uma forma ou de outra, trazem uma forma, na minha opinião, naturalizada, quer dizer, meio natural, meio óbvio, que a gente tem de lidar com conhecimentos prévios. E nesse último grupo também teve a fala de saber os conhecimentos prévios, e depois teve umas perguntas abre aspas 'para despertar', eu adorei, perguntas para despertar, eu adorei mesmo. Mas vocês falaram isso de uma forma muito bonita dizendo, tem uma coisa que é perguntas nós sabermos do conhecimento prévio do aluno e tem perguntas para despertar, quer dizer que são perguntas do campo mais da retórica, você pergunta pra pessoa pensar, pensar o tempo todo, é minha função como professora. E essa minha pergunta: 'o que fazer com o conhecimento prévio do aluno?' Muito pouco que nós estamos na nossa função docente, que estamos dispostos a ouvir o aluno. Não estou falando de você, estou falando de mim (Professora 04/10/2017 9:51 - grifo nosso). 
Edição Especial: I SSAPEC - Simpósio Sul-Americano de Pesquisa em Ensino de Ciências

Nesse trecho, a professora-formadora critica os efeitos do uso dos conhecimentos prévios nos planejamentos, como muito "óbvia", "natural" e "naturalizada". Seu movimento faz ponderar sobre outros modos de ação desse actante de modo a promover outros efeitos na rede, como ela mesmo sugere: "perguntas para despertar", "pra pessoa pensar" e "ouvir o aluno", as quais, em sua opinião, seriam muito mais interessantes, sendo essa, inclusive, uma "função docente". Dessa forma, “os conhecimentos prévios" entendidos como actantes (LATOUR, 2012) nos permitem entender que eles imprimem sua agência e, também, sofrem o efeito das manipulações pelos atores humanos e outros actantes, licenciandos, conteúdos de ensino, professoraformadora, sala de aula e alunos da educação básica. Nessas (des)associações, eles vão mobilizando (e sendo mobilizados) por uma série de outras entidades, conferindo contornos ao plano de aula, alterando, assim, o curso da informação e atuando como mediadores (LATOUR, 2012) nas redes da sala de aula.

Além disso, notamos, ainda, que, com a intervenção da professora-formadora, os "conhecimentos prévios" são acionados em uma tentativa de articular saberes experimentais (TARDIF, 2014) dos professores quando são trazidas, para aquele momento de formação, situações típicas do ambiente escolar, da sala de aula e das relações com os alunos: o que fazer com esses conhecimentos prévios em sala de aula? Portanto, a professora-formadora assume a disciplina acadêmica, incluída como carga horária de PCC, como um espaço-tempo de se pensarem, refletirem e problematizarem questões inerentes do contexto escolar. Uma maneira de praticar o ensino, conforme sustentam Selles e Ferreira (2009), traz o potencial de se construir um aprendizado coletivo visando a superar certas ideias equivocadas de ensino e aprendizagem, as quais, muitas vezes, são assumidas de modos simples e acríticos.

A forma como se consideram os conhecimentos prévios em planejamentos de aula pode produzir efeitos distintos nas considerações metodológicas de ensino e no modo como os conhecimentos serão considerados nos processos de ensinoaprendizagem durante a aula (TEIXEIRA; SOBRAL, 2010). Campanário (2002) defende que a superação ou opções para a adoção dos conhecimentos como "ideias para despertar" ocorre de acordo com o próprio amadurecimento do que tem sido proposto pelo campo do ensino de Ciências. 
Como já nos lembram Mortimer e Carvalho (1996), a ideia de adotar os conhecimentos prévios como uma etapa ou estágio para superação das ideias dos discentes já foi muito explorada no campo do ensino de Ciências pelos movimentos denominados "mudança conceitual” (CAMPANÁRIO, 2002; GIL-PEREZ, 1994; POZO et al., 1991, dentre outros). Nesse aspecto, ao apresentar "perguntas para despertar" e argumentar a favor dessa proposta, a professora promove, então, um afastamento da proposta de criar um conflito de concepções visando a um abandono do que o aluno já sabe em direção a um conhecimento mais "elaborado" ou "científico" (MORTIMER; CARVALHO, 1996) para o exercício da reflexão do que se sabe, como se sabe e o que se pode fazer com isso. Em outras palavras, interagindo e articulando com os actantes presentes na rede dos planos de aula dos licenciandos, a professora cria oportunidades de refletir com os licenciandos sobre como eles articulam seus saberes docente em ação. Durante o movimento de planejar e apresentar aulas para os colegas, nessa etapa, ainda, há muita abertura para o desconhecido e, quem sabe, com significativas possibilidades de reflexão.

\section{CONSIDERAÇÕES FINAIS}

Neste texto, nós nos propusemos a entender como o conhecimento para a docência é produzido em um curso de Licenciatura em Ciências e Biologia durante interações entre professores em formação e professora-formadora em uma sala de aula universitária. Foi selecionado, para análise, o momento específico de apresentação de planejamentos de aula para alunos da educação básica, etapa fundamental da formação de futuros docentes muito presente em disciplinas de Práticas de Ensino nas licenciaturas.

Nossas análises indicam que, nesses momentos, houve uma série de atores humanos e não humanos (actantes) arregimentados pelos participantes, que deram direcionamentos e contornos à prática de ensino performada naquele instante. Como destaque, apontamos as ações de três actantes, os quais demonstraram certo protagonismo: a licencianda Brenda, a professora-formadora e os conhecimentos prévios.

A rede erguida pelos atores naquele instante se organiza em torno do questionamento da docente: "o que fazemos com esses conhecimentos prévios dos Recebido em: 18/01/2021 
alunos?" Alterando a performance de um ator-rede, é, também, modificada toda direção do curso das ações das interações em sala de aula. Destaca-se, pois, a importância da atuação dos formadores de professores quando estes permitem "desestabilizar" ou "ressignificar" aquilo que é tomado de forma automática, acrítica ou não ideal pelos professores em formação durante etapas de construção de saberes para a docência ao mesmo tempo, em suas ações precedentes, que permitem criar apontamentos na direção de orientações mais ideias ou hegemônicas no campo da formação de professores e da Educação em Ciências.

\section{REFERÊNCIAS}

ANDRADE, E. P.; FERREIRA, M. S.; VILELLA, M. L.; AYRES, A. C. M.; SELLES, S. L. E. A dimensão da prática na formação inicial docente em Ciências Biológicas e em História: modelos formativos em disputa. Ensino em Revista, Uberlândia, v. 12, n. 1, p. 7-21, 2004.

AYRES, A. C. M.; VILELA, M. L.; SELlES, S. E. Formação de Professores de Ciências e Biologia: legislações e profissionalidade docente. In: VILELA, M. L.; MENDES, R. R. L.; PINHÃO, F. L.; RIOS, N. T. (Org.). Aqui também tem Currículo! Saberes em diálogo no ensino de Biologia. 1. ed. Curitiba, PR: Appris, 2020. v. 1, p. 101-120.

BOGDAN, R. C.; BIKLEN, S. K. Investigação qualitativa em educação - uma introdução às teorias e aos métodos. Porto: Porto Editora, 1994.

BOTON, J.; TOLENTINO-NETO, L. O que falam os trabalhos sobre Prática como Componente Curricular? Revista Insignare Scientia - RIS, v. 2, n. 2, p. 1-21, 16 set. 2019.

BRASIL. Ministério da Educação. Conselho Nacional de Educação. Resolução $\mathrm{CNE} / \mathrm{CP} \mathbf{n}^{\circ}$ 1, de 18 de fevereiro de 2002. Institui Diretrizes Curriculares Nacionais para a Formação de Professores da Educação Básica, em nível superior, curso de licenciatura, de graduação plena. Brasília: MEC/CNE, 2002a. Disponível em: <http://portal. mec.gov.br/cne/arquivos/pdf/rcp01_02.pdf>. Acesso em: 30 nov. 2020.

BRASIL. Ministério da Educação. Conselho Nacional de Educação. Resolução $\mathrm{CNE} / \mathrm{CP} \mathbf{n}^{\circ}$ 2, de 19 de fevereiro de 2002. Institui a duração e a carga horária dos cursos de licenciatura, de graduação plena, de formação de professores da Educação Básica em nível superior. Brasília: MEC/CNE, 2002b. Disponível em: <http://portal. mec.gov.br/cne/arquivos/pdf/rcp01_02.pdf>. Acesso em: 30 nov. 2020.

BRASIL. Ministério da Educação. Conselho Nacional de Educação. Resolução CNE/CP $n^{0}$ 02/2015, de $1^{0}$ de julho de 2015. Define as Diretrizes Curriculares Nacionais para a formação inicial em nível superior (cursos de licenciatura, cursos de formação pedagógica para graduados e cursos de segunda licenciatura) e para a Recebido em: 18/01/2021

Aceito em: 24/02/2021 
formação continuada. Diário Oficial da União, Brasília, 2 de julho de 2015 - Seção 1, p. 8-12. Disponível em: <http://portal.mec.gov.br/docman/agosto-2017-pdf/70431-res-cnecp-002-03072015 pdf/file>. Acesso em: 30 nov. 2020

BRASIL. Ministério da Educação. Conselho Nacional de Educação. Resolução CNE/CP n' 02/2019, de 20 de dezembro de 2019. Define as Diretrizes Curriculares Nacionais para a Formação Inicial de Professores para a Educação Básica e institui a Base Nacional Comum para a Formação Inicial de Professores da Educação Básica (BNC-Formação). Diário Oficial da União, Brasília, 23 de dezembro de 2019 - Seção 1, p. 115-119. Disponível em: <http://portal.mec.gov.br/component/content/article?id=77781\%E2\%80\%9D>. Acesso em: 30 nov. 2020.

CAMPANÁRIO, J. M. La enseñanza de las ciencias en perguntas y respuestas. Madrid, 2002. Disponível em: <http://www2.uah.es/jms/webens/portada.html>. Acesso em: 10 dez. 2020.

FENWICK, T.; EDWARDS, R. Actor-Network Theory in Education. London: Routledge, 2010.

FERREIRA, M. S.; VILELA, M. L.; SELLES, S. E. Formação docente em Ciências Biológicas: estabelecendo relações entre a prática de ensino e o contexto escolar. In: SELLES, S. E.; FERREIRA, M. S. (Org.). Formação Docente em Ciências: Memórias e Práticas. Niterói: EDUFF, 2003. v. 1, p. 29-46.

GATTI, B. A.; BARRETO, E. S. S. (Coord.). Professores do Brasil: impasses e desafios. Brasília: UNESCO, 2009. 294 p.

GATTI, B. A. et al. Formação de professores para o ensino fundamental: instituições formadoras e seus currículos. Estudos \& Pesquisas Educacionais, São Paulo: Fundação Victor Civita, n. 1, p. 95-138, 2010.

GAUTHIER, C. et al. Por uma teoria da pedagogia: pesquisas contemporâneas sobre o saber docente. Ijuí: Edunijuí, 2006.

GIL-PEREZ, D. Diez años de investigación en didáctica de las ciencia: realizaciones y perspectivas. Enseñanza de Las Ciências, Barcelona, v. 12, n. 2, p. 154-164, 1994.

HARMAN, G. The importance of Bruno Latour for philosophy, Cultural Studies Review, vol. 13, no. 1: 31-49. 2007.

LATOUR, B. Ciência em ação: como seguir cientistas e engenheiros sociedade afora. São Paulo: Ed. da Unesp, 2000.

LATOUR, B. Reagregando o social. Bauru, SP: EDUSC; Salvador, BA: EDUFBA, 2012.

LATOUR, B.; WOOLGAR, S. A vida de laboratório: a produção dos fatos científicos. Rio de Janeiro: Relume Dumará, 1997. 
LÜDKE, M.; ANDRÉ, M. E. D. A. Pesquisas em Educação: abordagens qualitativas. São Paulo: E.P.U, 2017.

MORTIMER, E. F.; CARVALHO, A. M. P. Referenciais teóricos para análise do processo de ensino de Ciências. Cadernos de Pesquisa, n. 96, p. 5-14, 1996.

PEREIRA, B.; MOHR, A. Concepção, proposta e execução da Prática como Componente Curricular no curso de graduação de Ciências Biológicas da Universidade Federal de Santa Catarina. In: MOHR, A.; WIELEWICHI, H. G. (Org.). Prática como Componente Curricular: que novidade é essa 15 anos depois? 1. ed. Florianópolis: NUP/CED/UFSC, p. 19 - 38, 2017.

POZO, J. A.; SANZ, A.; GÓMEZ CRESPO, M. A.; LIMÓN, M. Las ideas de los alumnos sobre la ciencia: un interretación desde la psicología cognitiva. Enseñanza de las Ciências, Barcelona, v. 9, n. 1, p. 83-94, 1991.

SELLES, S. E.; FERREIRA, M. S. Saberes docentes e disciplinas escolares na formação de professores em Ciências e Biologia. In: SELLES, S. E.; FERREIRA, M. S.; BARZANO, M. A. L.; SILVA, E. P. de Q. e (Org.). Ensino de Biologia: histórias, saberes e práticas formativas. Uberlândia: EDUFU, 2009. v. 1, p. 49-69.

SILVA, F. A. R. e; COUTINHO, F. Â. Realidades colaterais e produção da ignorância em livros didáticos de Biologia: um estudo sobre hormônios e a questão de gênero. Investigações em Ensino de Ciências (Online), v. 21, p. 176-194, 2016. Disponível em: https://www.if.ufrgs.br/cref/ojs/index.php/ienci/article/view/179/449 Acesso em: 18 dez. 2020.

SØRENSEN, E. The Materiality of Learning: technology and knowledge in educational practice. Cambridge: Cambridge University Press, 2009.

TARDIF, M. Saberes profissionais dos professores e conhecimentos universitários. Revista Brasileira de Educação, v. 13, n. 5, p. 5-24, 2000.

TARDIF, M. Saberes docentes e formação profissional. 17. ed. Petrópolis: Vozes, 2014.

TARDIF, M.; LESSARD, C. O trabalho docente: elementos para uma teoria da docência como profissão de interações humanas. Petrópolis: Vozes, 2005.

TEIXEIRA, F. M.; SOBRAL, A. C. M. B. Como novos conhecimentos podem ser construídos a partir dos conhecimentos prévios: um estudo de caso. Ciência \& Educação, v. 16, n. 3, p. 667-677, 2010.

TERRERI, L. Políticas curriculares para a formação de professores em Ciências Biológicas: investigando sentidos de prática. 2008. Dissertação (Mestrado em Educação) - Faculdade de Educação, Universidade Federal do Rio de Janeiro, Rio de Janeiro, 2008. 
Edição Especial: I SSAPEC - Simpósio Sul-Americano de Pesquisa em Ensino de Ciências

TERRERI, L.; FERREIRA, M. S. Políticas curriculares para a formação de professores: sentidos de teoria e prática nas Ciências Biológicas. Revista de Educação Pública (UFMT), v. 22, p. 999-1020, 2013.

VENANCIO, B. O.; VIANA, G. M. Concepções sobre a Prática como Componente Curricular nas atas dos ENPECS (2003-2013). Revista SBEnBio, v. 9, p. 1297-1309, 2016.

VENANCIO, B.; VIANA, G. M.; SILVA, F. A. R. e. Seguindo o rastro do tempo: um estudo ator-rede de performances de práticas de ensino de licenciandos em Ciências Biológicas. ACTIO, Curitiba, v. 5, n. 3, p. 1-19, set./dez. 2020. Disponível em: <https://periodicos.utfpr.edu.br/actio>. Acesso em: 20 dez. 2020.

VIANA, G. M.; COUTINHO, F. A. Prática como Componente Curricular: seguindo o conceito e analisando sua performance no currículo do curso de Licenciatura em Ciências Biológicas. In: MOHR, A.; WIELEWICHI, H. G. (Org.). Prática como Componente Curricular: que novidade é essa 15 anos depois? 1. ed. Florianópolis: NUP/CED/UFSC, p. 243-262, 2017.

VIANA, G. M.; MUNFORD, D.; FERREIRA, M. S.; FERNANDES, P. C. Relações teoria-prática na formação de professores de Ciências: um estudo das interações discursivas no interior de uma disciplina acadêmica. Archivos Analíticos de Políticas Educativas, v. 23, n. 100, p. 1-39, 2015. Disponível em: <http://dx.doi.org/10.14507/epaa.v23.2049>. Acesso em: 10 nov. 2020. 